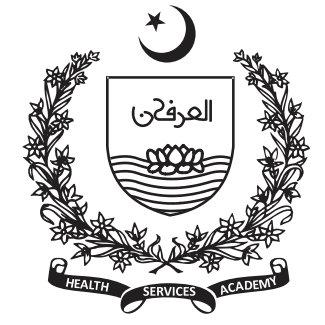

${ }^{1}$ MBBS Student, Sahiwal Medical College Sahiwal

2Sahiwal Medical College Sahiwal

Corresponding Author: Atiqa Khalid

Email:

atiqakhalid@slmc.edu.pk

\section{E-Learning: A Panacea during COVID- 19 Crisis}

\author{
Atiqa Khalid1, Sana $\mathrm{Ali}^{2}$
}

\section{Abstract}

Institute closure strategies were imposed during the COVID-19 pandemic worldwide to mitigate the rapid infection and transmission rate. E-learning was adapted as an alternative to traditional physical learning to keep the students safe from this infectious virus. While most of the countries have adopted this system, many under-developed and developing countries including Pakistan are not practicing the online system of E-learning as the biggest challenge to e-learning providers and policymakers is the provision of equal access to electronic-based learning to students from underprivileged backgrounds who have limited access to internet facility outside the learning institutions. School closure strategies during the COVID-19 pandemic must be based on equivocal evidence while implementing social distancing measures. If restrictive social distancing policies are to be imposed for a considerable period, other, less disruptive social distancing modes should be considered. The online learning system was a crucial step to balance academic loss in medical education. But our medical institutes are ill-equipped in implementing e-learning effectively. Authorities should devise ways to make e-learning more user-friendly.

Keywords: COVID-19 pandemic; Institutes closures; E-learning

\section{Introduction}

$\mathrm{I}$ nstitution closure strategies to reduce disease transmission have attracted considerable attention from the public health community. The closing of institutes at the beginning of influenza outbreaks was proposed as one of the safest ways to protect children and mitigate disease spread by preventing the vulnerable community with relatively poor hygiene to come into close contact. School closure strategies were implemented on evidence from the past outbreaks, especially the influenza epidemic, that they lessen physical connections between students and hamper disease transmissibility (1). Closing schools nationwide during the COVID-19 pandemic to mitigate its spread of SARS-CoV-2 was found to be of great importance. Investigators assessed the impact of the closing school on COVID-19 incidence and mortality and found that it was associated with a significant decline in incidence and mortality of COVID-19. Those Countries that closed schools earlier when the incidence of COVID-19 was low had seen a considerable impact to curb COVID-19 transmission (2). But the closing of schools has its own, critically important, effect on the functioning of society. Behavioral modifications and many simultaneous interventions have made it challenging to find the impact of school closures alone during the COVID-19 pandemic.

The UN Educational, Scientific, and Cultural Organization discovered on March 18, 2020, that 107 countries worldwide had imposed national institute closure strategies during the COVID-19 pandemic, and it has affected roughly half the global student population i.e. 862 million children and young people. A week before, only 29 countries had imposed this strategy (3). Pandemic preparedness planners are worried about outbreak-related work depletion. 
However, a study has shown that an alternative inschool approach can help control the disease without creating the same burden on society in finding alternative childcare. As some non-closure options may help in protecting the community, maintaining an optimized environment between limiting further infection and compromising the general function of society (4). Due to the COVID-19 crisis, approximately 1 billion students, including over 16 million learners in Central Asia, have been affected. As some of them could opt for online education, not all institutions were prepared to tackle this unprecedented educational disruption. Director of UNESCO Almaty, MS Krista Pillar urged - during a webinar series on education Sector response to COVID-19 - on developing high-quality digital content, improving digital educational platforms, and developing teachers' competencies for effective use of distance and online learning methods (5).

The influence of information technology on different aspects of our lives today is undeniable. Other countries have adopted the system of E-learning. Elearning is a means of learning by utilizing electronic technologies to access educational curriculum outside of a traditional classroom. The closure of educational institutions during COVID-19 and practicing elearning as an alternative to conventional physical learning is adapted to keep the students safe from this infectious virus. E-learning has its advantages due to its feasibility, flexibility, and better control over the environment. All this is increasing its overall acceptability. While many countries have adopted this system, many under-developed and developing countries are not practicing E-learning's online technique. According to UNESCO reports of March 2020, almost $80 \%$ of the population (1.3billion students) is affected by school closure in 138 countries (6).

To contain the spread of the COVID-19 pandemic, some of the closures are recent, while in the case of others, school closure strategies have been implemented at the beginning of the outbreak. In all cases, closures are placing unprecedented challenges on the government to ensure learning continuity and teachers, students, parents, and caregivers. Despite the worldwide adaptation of E-learning, it has never been considered part of formal education in Pakistan until the COVID-19 pandemic. Due to nationwide lockdown, all schools, colleges, and even medical and dental universities and have moved towards the system of online learning. Recognizing the academic loss caused by the cessation of learning activities, the Higher Education Commission (HEC) has proposed continuing education through online courses and lectures (8). Hence, medical institutes should also provide effective online learning environments to their students to balance the cessation of learning activities. Some medical institutes are effectively using the online teaching system, while others are irritated by the complexity of online learning. To achieve the desired results, e-learning engineering should be devised as highlighted by the Horizon 2020 report, which encompasses the various aspect of designing, implementing, and evaluating an us-er-friendly technology (7). The biggest challenge to e-learning providers and policymakers is the provision of equal access to electronic-based learning to students from underprivileged backgrounds who have limited access to internet facilities outside the learning institutions. Governments of various countries and policymakers are addressing these challenges. In China, computers were provided to students from low-income families. In France, 5\%students are supplied with printed assignments who don't have access to the internet and other devices. In the US, online learning services were ensured to students (9). Amid the COVID-19 pandemic, the e-learning platform system has tremendously remodeled and contrived how we teach and engage with our medical trainees. The COVID-19 pandemic and disruptions of the educational system are far from over. Almost 100 countries have not even announced the date for reopening the schools and universities. Across the world, the government, school administrations, and parents are grasping how to deal with the coming situation. Many Countries have started to reopen schools nationwide either by prioritizing grade level or only in those regions with low infectivity (1)

It will be interesting to explore that only traditional formal learning will be carried out after reopening, or both the online learning and standard system of education will be practiced side by side depending on the student's educational needs and time availability.

\section{Conclusion}

COVID-19 pandemic has created a profound impact on medical education worldwide. Medical education has been changed from traditional teaching to competency-based medical education involving 
regular assessment and clinical learning. Hence, the chairman HEC emphasized that formal training of faculty regarding online teaching is need of the hour (8)

School closure strategies during the COVID-19 pandemic must be based on equivocal evidence while implementing social distancing measures. If restrictive social distancing policies are to be imposed for a considerable period, other, less disruptive social distancing modes should be considered.

Different countries have imposed various public health and social measures (PHSM), including schools and businesses' closure and movement restrictions. As the disease's burden lessens, countries will adjust these measures according to the intensity of transmission. The World Health Organization has issued guidance on changing PHSM while managing the risk of the resurgence of cases. This annex can help educators and decision-makers in Pakistan to reopen or close schools in the COVID-19 pandemic (10).

In developed countries and regions where there is no hurdle to Internet access, the advantage of online education is evident as it enables schools to deliver courses online so that teachers can offer instructions, share learning resources, give quizzes, and many more. The stay-at-home learning and working modes have increased the time shared between parents and their children, making parents active engagement in supporting children's online learning experiences and communities involved in creating a favorable learning environment. The following online education guide tools can serve as a navigator for the people engaged in online education practice in the post-pandemic era (2). Microsoft OneNote, Microsoft Teams, Zoom Telegram, and Google-Suite are the widely used elearning software to help learners pursue their studies during this pandemic.

The online learning system was a crucial step to balance academic loss. But our medical institutes are ill-equipped to implement e-learning effectively. This rapid transition from face-to-face teaching to a flexible online learning environment was difficult to adapt due to inefficient internet in the rural areas and lack of previous experience and technology awareness, especially among older faculty, untrained faculty, poor internet connection, the unfriendliness of teachers and students with new technology, and unavailability of personal computers by students. The cornerstone of medical education, including laboratory procedures, clinical skill teaching, professional competency, practices, physical interaction between teachers and students, and bedside teaching, seems to be compromised in Elearning. Moreover, it's still unclear how students will be accessed online.

Authorities must devise ways to make e-learning more user-friendly. Reopening the schools using a controlled public health approach, including social distancing and prevention strategies, would lead to an increase in the transmission is not clear. A tremendous challenge is to balance the loss of academic progress, social development, and the risk of spreading reinfection in the students (11). It will be interesting to explore that only traditional formal learning will be carried out after reopening, or both the online education and standard system of knowledge will be practiced side by side depending on the student's educational needs and time availability. The crisis would be overcome soon, and that schools would be reopened so that students and teachers could continue their learning and teaching in a healthy and comfortable environment (12).

\section{References}

1. Jackson C, Vynnycky E, Mangtani P. The relationship between school holidays and transmission of influenza in England and wales. American journal of epidemiology. 2016 Nov 1;184(9):644-51.

2. Auger KA, Shah SS, Richardson T, Hartley D, Hall M, Warniment A, et al. Association Between Statewide School Closure and COVID-19 Incidence and Mortality in the US. JAMA. 2020 Sep 1;324(9):859-70.

3 United Nations Educational Scientific and Cultural Organization COVID-19 educational disruption and response. https://en.unesco.org/themes/educationemergencies/coronavirus-school-closures Date accessed: November 30, 2020

4. Lofgren ET, Rogers J, Senese M, Fefferman NH. Pandemic preparedness strategies for school systems: is closure really the only way? InAnnales Zoologici Fennici 2008 Oct (Vol. 45, No. 5, pp. 449-458). Finnish Zoological and Botanical Publishing Board.

5. UNESCO. UNESCO organized the first in a series of online trainings on distance learning solutions for Central Asian countries - UNESCO IITE [Internet]. 2020b [cited 2020 Nov 30]. Available from: https://iite.unesco.org/news/unesco-organized-theonline-training-on-distance-learning-solutions-forcentral-asia/ 
6. Almarzooq Zaid I., Lopes Mathew, Kochar Ajar. Virtual Learning During the COVID-19 Pandemic. J Am Coll Cardiol. 2020 May 26;75(20):2635-8.

7. Badwan B, Bothara R, Latijnhouwers M, Smithies A, Sandars J. The importance of design thinking in medical education. Med Teach [Internet]. 2018; 40(4):425-426. https://doi.org/10.1080/ 0142159X. 2017.1399203

8. Higher Education Commission. HEC COVID-19 Policy Papers. $2020 \quad$ [cited 2020Aug17]. https://www.hec.gov.pk/english/HECAnnouncement s/Documents/nCoVirus/Covid-19-Policy-GuidanceNo.5-Online Readiness.pdf
9. United Nations. Policy Brief: Education during COVID19 and beyond (August 2020) - World | ReliefWeb. 2020;(August).

10. Reimers F, Schleicher A, Saavedra J, Tuominen S. Supporting the continuation of teaching and learning during the COVID-19 pandemic. Oecd. 2020;1-38.

11. Khalid A, Ali S. COVID-19 and its Challenges for the Healthcare System in Pakistan. Asian Bioeth Rev. 2020 Dec;12(4):551-64.

12. Gul H, Ijaz A, Khalid A, Khan T. Knowledge, attitude, and perception of University students toward COVID19 Pandemic. Pak J Surg Med. 2020 Oct 22;1(3):e148. 